Chemistry for Sustainable Development 

Minu Gupta Bhowon - Sabina Jhaumeer-Laulloo Henri Li Kam Wah • Ponnadurai Ramasami Editors

\section{Chemistry for Sustainable Development}

Springer 


\section{Editors}

Dr Minu Gupta Bhowon

Department of Chemistry

University of Mauritius, Réduit

Mauritius

mbhowon@uom.ac.mu

Dr Henri Li Kam Wah

Department of Chemistry

University of Mauritius, Réduit

Mauritius

lkwah@uom.ac.mu
Dr Sabina Jhaumeer-Laulloo

Department of Chemistry

University of Mauritius, Réduit

Mauritius

sabina@uom.ac.mu

Dr Ponnadurai Ramasami

Department of Chemistry

University of Mauritius, Réduit

Mauritius

p.ramasami@uom.ac.mu

ISBN 978-90-481-8649-5

e-ISBN 978-90-481-8650-1

DOI 10.1007/978-90-481-8650-1

Springer Dordrecht Heidelberg London New York

Library of Congress Control Number: 2011939768

(c) Springer Science+Business Media B.V. 2012

No part of this work may be reproduced, stored in a retrieval system, or transmitted in any form or by any means, electronic, mechanical, photocopying, microfilming, recording or otherwise, without written permission from the Publisher, with the exception of any material supplied specifically for the purpose of being entered and executed on a computer system, for exclusive use by the purchaser of the work.

Printed on acid-free paper

Springer is part of Springer Science+Business Media (www.springer.com) 


\section{Preface}

The International Conference on Pure and Applied Chemistry (ICPAC 2010) was held from 26th to 30th July 2010 at La Plantation Resort and Spa, Balaclava, in Mauritius. The theme of the conference was "Chemistry for Sustainable Development". ICPAC 2010 was attended by about 160 participants coming from 30 countries. The conference featured 100 oral and 85 poster presentations.

The participants of ICPAC 2010 were invited to submit full papers. The latter were subsequently peer reviewed and the selected papers are collected in this volume.

This book of proceedings encloses 31 presentations covering wide ranging topics from organic chemistry to material science and nanotechnology, and from computational chemistry to agricultural chemistry.

We would like to thank all those who submitted the full papers and the reviewers for their timely help in assessing these papers for publication.

We would like to pay a special tribute to all the sponsors of ICPAC 2010.

Chemistry is being increasingly recognised as a central discipline that encompasses several areas of medicine, agriculture, biology, environment, physics and material science. Therefore, as we celebrate the International Year of Chemistry (IYC 2011) and the 100th anniversary of the Noble prize awarded to Marie Curie, we hope that this collection of papers will serve as a useful reference set for researchers.

Gupta Bhowon, M Jhaumeer-Laulloo, S

Li Kam Wah, H Ramasami, P 



\section{Contents}

1 Investigation of Dissolved Nutrients in Tropical Coastal Waters in Mauritius

Zaynab B. Bissembur, Janita Balgobin, Archana Anjore,

Roshan T. Ramessur, and Kishore Boodhoo

2 The Influence of the Cage Effect on the Mechanism of Multistage Chemical Reactions in Solutions

Alexander B. Doktorov and Stanislav G. Fedorenko

3 Photoionization Studies of Reactive Intermediates of Importance in the Atmosphere

John Dyke

4 Synthesis and Applications of Nano Size Titanium Oxide and Cobalt Doped Titanium Oxide

Revannath D. Nikam, Sharad S. Gaikwad, Ganesh E. Patil, Gotan H. Jain, and Vishwas B. Gaikwad

5 Development of Novel Insect Growth Regulators: Effect of 1-(Substitutedbenzoyl)-3-[(2'-Isopropyl5'-Methylphenoxy) Acetamino] Thiourea and Urea Derivatives on Total Haemocyte Count of Dysdercus koenigii ........ Chetan M. Zade, Umesh D. Pete, Megharaj S. Kadam, and Ratnamala S. Bendre

6 Preliminary Catalytic Studies Using Tyrosine and Phenylalanine Analogues on Selected Baylis-Hillman and Michael Reactions

Prakashanand Caumul, Nausheen Joondan, Anuradha Tuhaloo, and Thavinash Jhowry 
7 Synthesis, Structure and Characterization of New Amic Acid Derivatives of 3-Amino-1,2,4-Triazole and Their Complexes with Some Metal Ions.

Ahlam J. Abdulghani and Suad M. Sahan

8 Regioselective Synthesis of Polyfluorinated Pyrazoles and Evaluation of Antimicrobial Activity...

Madhukar N. Jachak, Dilip R. Birari, Deepak P. Shelar, Sandeep R. Patil, Ramhari V. Rote, Santosh S. Shinde, and Sandip M. Bagul

9 Trapping of Organomanganese Generated Enolates with an Aldehydes in the Presence of $\mathrm{Cu}(\mathrm{NCMe})_{4}\left[\mathrm{BF}_{4}\right]$

Sunil D. Jadhav and Madhukar B. Deshmukh

10 Radial and Electron Correlation Effects for Helium and Some Helium Like Ions

Khalil H. AL-bayati and Esraa F. Saeed

11 Dynamical Role of the Fictitious Orbital Mass in Car-Parrinello Molecular Dynamics

Sheau-Wei Ong, Eng-Soon Tok, and H. Chuan Kang

12 Novel Liquid Diffusion Tube Determines Electrolytes'

Relative Free Diffusion Velocities, Hydration Numbers and Overwhelmingly Revalidates Electrolytic Diffusion Law

Abul Khair, Golam M. Golzar Hossain, Mohammad S. Alam, Mahammad M. Hossain, Mohammad H. Kabir, Mohammad H. Rahman, and Amal Halder

13 Reverse Phase Extraction Chromatographic Separation of Trivalent Bismuth Using Liquid Anion Exchanger

Sachin R. Phule, Haribhau R. Aher, Shamrao P. Lawande, and Shashikant R. Kuchekar

14 Dry Sliding Wear Behavior of Ultrafine-Grained Mild Steel Processed Using Multi Axial Forging

Aditya K. Padap, Gajanan P. Chaudhari, and Sumeer K. Nath

15 Thiocyanato Bridged Heterodinuclear Complex

$\left[\mathrm{Cu}(\mathrm{bpy})_{2}(\mu-\mathrm{NCS}) \mathrm{Ru}(\mathrm{bpy})_{2}\left(\mathrm{NO}_{3}\right)\right]\left(\mathrm{PF}_{6}\right)_{2}$ and Its Binding with $\mathrm{Cd}(\mathrm{II}), \mathrm{Hg}(\mathrm{II}), \mathrm{Pb}(\mathrm{II})$ and $\mathrm{Ag}(\mathrm{I})$ Ions

Niraj Kumari, Mudit Dixit, Herbert W. Roesky, and Lallan Mishra 
16 Using Electrochemical Impedance Spectroscopy of Methylene Blue and Ferricyanide for DNA Sensing Surface Characterization

Suthisa Leasen, Kallaya Sritunyalucksana-Dangtip,

Jose H. Hodak, Jiraporn Srisala, Chadin Kulsing, and Waret Veerasia

17 An Investigation into the Use of the Concept Attainment Model in Teaching the "Periodic Table" at ' $O$ '-Level Through an Action Research 265

Mokshada Luckpoteea and Fawzia B. Narod

18 Synthesis, Spectral Characterization and Anticancer Screening of Triorganotin(IV) Carboxylates Mala Nath, Monika Vats, and Partha Roy

19 Nonequilibrium Ultrafast Charge Transfer Reactions in Photoexcited Donor-Acceptor Pairs

Valentina A. Mikhailova, Sergey V. Feskov, Vladimir N. Ionkin, Vladislav V. Yudanov, and Anatoly I. Ivanov

20 Adsorption Studies of Lead, Copper and Cadmiun Ions in Aqueous Solution by Ethylene Diamine Modified Amberlite XAD-1180

Isaac W. Mwangi, Jane C. Ngila, Joseph Kamau, and Jonathan Okonkwo

21 Theoretical Study of Structure, Vibration Spectra and Thermodynamic Properties of Cluster Ions in Vapors over Potassium, Rubidium and Cesium Chlorides...

Tatiana P. Pogrebnaya, Jean B. Hishamunda, Camille Girabawe, and Alexander M. Pogrebnoi

22 Environmental Threat to Photochemical and Photobiological Reactions

Rafia Azmat

23 Neutral-Neutral Direct Hydroamination Reactions of Substituted Alkenes: A Computational Study on the Markovnikov Selection Rule

Sanyasi Sitha and Linda L. Jewell

24 Preparation and Characterization of $\mathrm{TiO}_{2}-\mathrm{ZrO}_{2}$ Mixed Oxide Catalysts for Photocatalytic Reduction of Carbon Dioxide

Simona Krejcikova, Kamila Koci, Lucie Obalova,

Libor Capek, and Olga Solcova 
25 Modification of Anthraquinone-2-Carboxylic Acid with

Multiwalled Carbon Nanotubes and Electrocatalytic

Behavior of Prepared Nanocomposite Towards Oxygen Reduction .. 399

Ida Tiwari, Manorama Singh, and Mandakini Gupta

26 Synthesis and Biological Activity of Derivatives of $2,2^{\prime}$-Dithiobisbenzamides

Roumilla Gungah, Salma Moosun, Sabina Jhaumeer-Laulloo, and Minu G. Bhowon

27 Spectral Studies of Solar Radiation Induced Dye Decoloration in Aqueous Solution

Fahim Uddin, Rafia Azmat, and Tehseen Ahmed

28 Optimization of Process Parameters for Enhanced Decolorization of NOVASOL Direct Black Textile Dye by Agaricus bitorqus

Haq N. Bhatti and Ismat Bibi

29 Chemical Composition and Antimicrobial Activity of Comorian Ocimum canum Essential Oil Harvested in the Region of Maweni Dimani-Grande Comoros.

S.O.S. Hassane, A. Farah, B. Satrani, M. Ghanmi, N. Chahmi, S.H. Soidrou, and A. Chaouch

30 Synthesis of Five-, Six- and Seven-Membered Hetero Ring Annulated Imidazo[4,5-b] carbazoles and Azacarbazoles of Medicinal Interest

Bhawani Singh, Bharti Vashishtha, and D. Kishore

31 Screening Biochemical Markers for the Prevention of Coronary Heart Disease

Deepuk Albana and Marie Chan Sun

Index 


\section{Contributors}

Ahlam J. Abdulghani Department of Chemistry, College of Science, University of Baghdad, Jaderiya, Baghdad, Iraq, prophahlam@yahoo.com

S. M. Achmet School of Chemistry, University College of Science, University of Tehran, Tehran, Iran

Haribhau R. Aher P. G. Department of Analytical Chemistry, P. V. P. College Pravaranagar, At/Po. Loni (Kd), Tal. Rahata, Dist. Ahmednagar, 413713 Maharashtra, India, h_aher@yahoo.com

Tehsenn Ahmed Department of Chemistry, University of Karachi, Karachi, 75270 Pakistan, chemist_physical@yahoo.com

Khalil H. AL-bayati Department of Physics, College of Science for Women, Baghdad University, Aljadyria, Baghdad, Iraq, drkhalilhadi@yahoo.com

Mohammad S. Alam Department of Applied Chemistry \& Chemical Engineering, Noakhali Science and Technology University, Sonapur, Noakhali, Bangladesh

Deepuk Albana C/o mr Ravin Albana, 122 Caroline Road, Vallee des Pretres, Port Louis, Mauritius

Archana Anjore Department of Chemistry, University of Mauritius, Réduit, Mauritius

Rafia Azmat Department of Chemistry, Jinnah University for Women, 5C Nazimabad, Karachi, 74600 Pakistan, rafiasaeed200@yahoo.com

Sandip M. Bagul Organic Chemistry Research Centre, Department of Chemistry, K. T. H. M. College, Gangapur Road, Nashik 422 002, Maharashtra, India, sandipbagul@gmail.com

Janita Balgobin Department of Chemistry, University of Mauritius, Réduit, Mauritius, j1_balgobin@yahoo.com 
Ratnamala S. Bendre School of Chemical Sciences, North Maharashtra University, Jalgaon, 425001 India, bendrers@ rediffmail.com

Haq N. Bhatti Department of Chemistry \& Biochemistry, University of Agriculture, Faisalabad, 38040 Pakistan, hnbhatti2005@yahoo.com

Minu G. Bhowon Department of Chemistry, Faculty of Science, University of Mauritius, Reduit, Mauritius, mbhowon@uom.ac.mu

Ismat Bibi Department of Chemistry \& Biochemistry, University of Agriculture, Faisalabad, 38040 Pakistan, ismat16_08_1982@yahoo.com

Dilip R. Birari Organic Chemistry Research Centre, Department of Chemistry, K. T. H. M. College, Gangapur Road, Nashik 422 002, Maharashtra, India, dilip.birari@cipla.com

Zaynab B. Bissembur Department of Chemistry, University of Mauritius, Réduit, Mauritius, zeinabiss72@yahoo.com

Kishore Boodhoo Department of Chemistry, University of Mauritius, Réduit, Mauritius, kishore.boodhoo@uom.ac.mu

Libor Capek Faculty of Chemical Technology, Univerzity of Pardubice, Studentská, 95, Pardubice, Czech Republic, libor.capek@upce.cz

Prakashanand Caumul Department of Chemistry, Faculty of Science, University of Mauritius, Réduit, Mauritius, p.caumul@uom.ac.mu

N. Chahmi National Institute of Medicinal and Aromatic Plants - Taounate, BP 159, Tounate Principale, Sidi Mohamed Ben Abdallah University, Fes Maroc

A. Chaouch Laboratory of Applied Chemistry and Quality Control, Faculty of Science, Université Ibn Tofail, BP133 Kenitra, Morocco

Gajanan P. Chaudhari Department of Metallurgical and Materials Engineering, Indian Institute of Technology Roorkee, Roorkee, Uttarakhand, 247667 India, chaudfmt@iitr.ernet.in

Madhukar B. Deshmukh Department of Chemistry, Shivaji University, Belgaum Road, 416004 Kolhapur, India, m_deshmukh1@ @rediffmail.com

Mudit Dixit Electronic Structure and Theory Group, National Chemical Laboratory, 441008 Pune, India, dixitmuditk@gmail.com

Alexander B. Doktorov Laboratory of Theoretical Chemistry, Institute of Chemical Kinetics and Combustion SB RAS, Institutskaya 3, 630090 Novosibirsk, Russia, doktorov@kinetics.nsc.ru

John Dyke School of Chemistry, University of Southampton, Southampton, SO17 1BJ UK,jmdyke@soton.ac.uk

A. Farah Department of Chemistry, CCB124, York University, 4700 Keele St., Toronto, ON, M3J1P3 Canada 
Stanislav G. Fedorenko Laboratory of Theoretical Chemistry, Institute of Chemical Kinetics and Combustion SB RAS, Institutskaya 3, 630090 Novosibirsk, Russia, fedorenk@kinetics.nsc.ru

Sergey V. Feskov Physical-Technical Institute, Volgograd State University, University Avenue, 400062 Volgograd, Russia, serguei.feskov@ volsu.ru

Sharad S. Gaikwad Department of Chemistry, K.T.H.M.College, Gangapur Road, Nashik, Maharastra, 422002 India, gaikwad.sharad85@gmail.com

Vishwas B. Gaikwad Chemistry Materials Research Laboratory, K. T. H. M. College, Nashik, Maharashtra, 422022 India, dr.gaikwadvb@ rediffmail.com

M. Ghanmi Laboratoire de Chimie des Plantes et Synthèse organique et Bioorganique, Faculté des Sciences, Université Mohammed V-Agdal, BP1014 Rabat, Morocco

Camille Girabawe Roumilla Gungah Department of Chemistry, Faculty of Science, University of Mauritius, Reduit, Mauritius, rumilla_777@yahoo.com

Mandakini Gupta Department of Chemistry, Faculty of Science, Banaras Hindu University, Varanasi, 221005 India, mandakini1710@gmail.com

Amal Halder Department of Chemistry, University of Burdwan, Bardhaman, India

S. O. S. Hassane Faculty of Science and Technology, University of the Comoros, BP 2585 Moroni, Comoros, Comorossaid_omar2000@yahoo.fr

Jean B. Hishamunda Physics Department, Brandeis University, Waltham, MA 02453, USA

Jose H. Hodak Facultad de Ciencias Exacts y Naturales, Ciudad Univeritaria Pab., Universidad de Buenos Aires, 1428 Buenos Aires, Argentina, josew3@yahoo.com

Golam M. Golzar Hossain School of Chemistry, Cardiff University, Cardiff, CF10 3AT UK

Mahammad M. Hossain Department of Chemical Engineering, Mohamed Sathak Engineering College, Kilakarai, 623806 India

Vladimir N. Ionkin Physical-Technical Institute, Volgograd State University, University Avenue, 400062 Volgograd, Russia, ionya@mail.ru

Anatoly I. Ivanov Physical-Technical Institute, Volgograd State University, University Avenue, 400062 Volgograd, Russia, Anatoly.Ivanov@ volsu.ru

Madhukar N. Jachak Organic Chemistry Research Centre, Department of Chemistry, K. T. H. M. College, Gangapur Road, Nashik 422 002, Maharashtra, India, mnjachak@hotmail.com

Sunil D. Jadhav Department of Chemistry, Dada Patil Mahavidyalaya, Karjat, 414402 Maharashtra, India, jadhav.sd@ rediffmail.com 
Gotan H. Jain Department of Physics, Arts, Commerce \& Science College, Nandgaon, Nashik, Maharastra, 423106 India, gotanjain@ rediffmail.com

Linda L. Jewell School of Chemical and Metallurgical Engineerinig, University of the Witwatersrand, Private Bag 3, Wits 2050 Johannesburg, South Africa, linda.jewell@wits.ac.za

Sabina Jhaumeer-Laulloo Department of Chemistry, Faculty of Science, University of Mauritius, Reduit, Mauritius, sabina@uom.ac.mu

Thavinash Jhowry Department of Chemistry, Faculty of Science, University of Mauritius, Réduit, Mauritius

Nausheen Joondan Department of Chemistry, Faculty of Science, University of Mauritius, Réduit, Mauritius

Mohammad H. Kabir Department of Microbiology, University of Dhaka, Dhaka, Bangladesh

Megharaj S. Kadam School of Life Sciences, North Maharashtra University, Jalgaon, 425001 India, ms.kadam@gmail.com

Joseph Kamau School of Chemistry, University of KwaZulu-Natal, University Road, Westville, P/Bag X45001, Durban, 4000 South Africa, josephkamau@yahoo.com

H. Chuan Kang Department of Chemistry, National University of Singapore, 3 Science Drive 3, 117543 Singapore, Singapore, chmkhc@nus.edu.sg

Abul Khair Department of Chemistry, University of Dhaka, Dhaka, 1000 Bangladesh, profabulkhair@gmail.com

D. Kishore Department of Chemistry, Banasthali University, Banasthali, Rajasthan, 304022 India, kishoredharma@yahoo.co.in

Kamila Koci Department of Physical Chemistry and Theory of Technological Processes, Technical University of Ostrava, 17. Listopadu, 15, Ostrava, Czech Republic, kamila.koci@vsb.cz

Simona Krejcikova Department of Catalysis and Reaction Engineering, Institute of Chemical Process Fundamentals of the ASCR, v.v.i., Rozvojova, 135, Prague 6, Czech Republic, krejcikova.simona@icpf.cas.cz

Shashikant R. Kuchekar P. G. Department of Analytical Chemistry, P. V. P. College Pravaranagar, At/Po. Loni (Kd), Tal. Rahata, Dist. Ahmednagar, 413713 MS, India, shashi17@gmail.com

Chadin Kulsing IFEC-MU, Mahidol University, Rama VI Road Thung Phyathai Rachadevi, 10400 Bangkok, Thailand, payoonum@yahoo.com

Niraj Kumari Department of Chemistry, Banaras Hindu University, 221005 Varanasi, India, nirajchem@gmail.com 
Shamrao P. Lawande P. G. Department of Analytical Chemistry, P. V. P. College Pravaranagar, At/Po. Loni (Kd), Tal. Rahata, Dist. Ahmednagar, 413713 MS, India

Suthisa Leasen Department of Physics, Mahidol University, Rama VI Road Thung Phyathai Rachadevi, 10400 Bangkok, Thailand, sainub@gmail.com

Mokshada Luckpoteea Simadree Virahsawmy State Secondary School, Rivière du Rempart, Mauritius, mokshada25@hotmail.com

Valentina A. Mikhailova Physical-Technical Institute, Volgograd State University, University Avenue, 400062 Volgograd, Russia, mixailova_va@mail.ru

Lallan Mishra Department of Chemistry, Banaras Hindu University, 221005 Varanasi, India, 1mishrabhu@yahoo.co.in

Salma Moosun Department of Chemistry, Faculty of Science, University of Mauritius, Reduit, Mauritius, salma2410@gmail.com

Isaac W. Mwangi School of Chemistry, University of KwaZulu-Natal, University Road, Westville, P/Bag X45001, Durban, 4000 South Africa, isaacwaweru2000@yahoo.co.uk

Fawzia B. Narod Department of Science Education, Mauritius Institute of Education, Mauritius, Mauritius, zia373@eudoramail.com

Mala Nath Department of Chemistry, Indian Institute of Technology Roorkee, Roorkee 247667, India, malanfcy@iitr.ernet.in

Sumeer K. Nath Department of Metallurgical and Materials Engineering, Indian Institute of Technology, Roorkee, Uttarakhand, 247667 India, indiafmt@iitr.ernet.in

J. Catherine Ngila School of Chemistry, University of KwaZulu-Natal, University Road, Westville, P/Bag X45001, Durban, 4000 South Africa, ngila@ukzn.ac.za

Revannath D. Nikam Department of Chemistry, K.T.H.M.College, Gangapur Road, Nashik, Maharastra, 422002 India, nikam.revan@ rediff.com

Lucie Obalova Dept.of Physical Chemistry and Theory of Technological Processes, Technical University of Ostrava, 17. Listopadu, 15, Ostrava, Czech Republic, lucie.obalova@vsb.cz

Jonathan Okonkwo Department of Environmental, Water \& Earth Science, Faculty of Science, Tshwane University of Technology, 175 Nelson Mandela Drive, P/Bag X680, Pretoria, 0001 South Africa, OkonkwoOJ@tut.ac.za

Sheau-Wei Ong Department of Chemistry, National University of Singapore, 3 Science Drive 3, 117543 Singapore, Singapore, chmosw@nus.edu.sg

Aditya K. Padap Department of Metallurgical and Materials Engineering, Indian Institute of Technology Roorkee, Roorkee, Uttarakhand, 247667 India

Ganesh E. Patil Department of Physics, Arts, Commerce \& Science College, Nandgaon, Nashik, Maharastra, 423106 India, ganeshpatil_phy@rediffmail.com 
Sandeep R. Patil Organic Chemistry Research Centre, Department of Chemistry, K. T. H. M. College, Gangapur Road, Nashik 422 002, Maharashtra, India, dr.sandeeppatil28@gmail.com

Umesh D. Pete School of Chemical Sciences, North Maharashtra University, Jalgaon, 425001 India, umeshdpete@rediffmail.com

Sachin R. Phule Department of Chemistry, P. V. P. College Pravaranagar, At/Po. Loni (Kd), Tal. Rahata, Dist. Ahmednagar, 413713 Maharashtra, India, sachinphule55@yahoo.co.in

Tatiana P. Pogrebnaya Ivanovo State University of Chemical Technology, Ivanovo, Russia

Alexander M. Pogrebnoi Department of Applied Physics, Kigali Institute of Science and Technology, Kigali, Rwanda,pgamtp@mail.ru

Mohammad H. Rahman Dr. Panjwani Center for Molecular Medicine and Drug Research (PCMD); International Center for Chemical and Biological Sciences (ICCBS), University of Karachi, Karachi, 75270 Pakistan, hafizur.rahman@iccs.edu

Roshan T. Ramessur Department of Chemistry, University of Mauritius, Réduit, Mauritius, ramessur@uom.ac.mu

H. W. Roesky Institute of Inorganic Chemistry, Goettingen University, Goettingen, Germany,hroesky@gwdg.de

Ramhari V. Rote Organic Chemistry Research Centre, Department of Chemistry, K. T. H. M. College, Gangapur Road, Nashik 422 002, Maharashtra, India, rote.ramhari509@rediffmail.com

Partha Roy Department of Biotechnology, Indian Institute of Technology Roorkee, Roorkee 247667, India, paroyfbs@iitr.ernet.in

Esraa F. Saeed Department of Physics, College of Science, Hahrain University, Aljadyria, Baghdad, Iraq, israa_physics2006@yahoo.com

Suad M. Sahan Department of Chemistry, College of Science, University of Baghdad, Jaderiya, Baghdad, Iraq

B. Satrani Centre de recherche forestière, BP 763, Agdal, 10050 Rabat, Morocco

Deepak P. Shelar Organic Chemistry Research Centre, Department of Chemistry, K. T. H. M. College, Gangapur Road, Nashik 422 002, Maharashtra, India, deeprity83@gmail.com

Santosh S. Shinde Organic Chemistry Research Centre, Department of Chemistry, K. T. H. M. College, Gangapur Road, Nashik 422 002, Maharashtra, India, sss.3s@rediffmaill.com

Bhawani Singh Department of Chemistry, Banasthali University, Banasthali, Rajasthan, 304022 India, bsyadav2000@gmail.com 
Manorama Singh Department of Chemistry, Faculty of Science, Banaras Hindu University, Varanasi, 221005 India, manoramabhu@gmail.com

Sanyasi Sitha School of Chemical and Metallurgical Engineering, University of the Witwatersrand, Private Bag 3, Wits 2050 Johannesburg, South Africa, sanyasi.sitha@wits.ac.za

S. H. Soidrou Olga Solcova Department of Catalysis and Reaction Engineering, Institute of Chemical Process Fundamentals of the ASCR, v.v.i., Rozvojova 135, Prague 6, Czech Republic, solcova@icpf.cas.cz

Jiraporn Srisala National Science and Technology Development Agency, National Center for Genetic Engineering and Biotechnology, Klongluang Province, 12120 Pathumthani, Thailand, jsrisala@gmail.com

Kallaya Sritunyalucksana-Dangtip Centex Shrimp, Mahidol University, Rama VI Road Thung Phyathai Rachadevi, 10400 Bangkok, Thailand, tekst@mahidol.ac.th

Marie Chan Sun Department of Medicine, University of Mauritius, Réduit, Mauritius, lan.sun@uom.ac.mu

Ida Tiwari Department of Chemistry, Faculty of Science, Banaras Hindu University, Varanasi, 221005 India, idatiwari_2001@rediffmail.com

Eng-Soon Tok Department of Physics, National University of Singapore, 3 Science Drive 3, 117543 Singapore, Singapore, phytokes@nus.edu.sg

Anuradha Tuhaloo Department of Chemistry, Faculty of Science, University of Mauritius, Réduit, Mauritius

Fahim Uddin Department of Chemistry, University of Karachi, Karachi, 75270 Pakistan, fahim_Uddin01@yahoo.com

Bharti Vashishtha Department of Chemistry, Banasthali University, Banasthali, Rajasthan, 304022 India, bhartivashishtha.chem@gmail.com

Monika Vats Department of Chemistry, Indian Institute of Technology Roorkee, Roorkee 247667, India, mona2k42000@gmail.com

Waret Veerasia IFEC-MU, Mahidol University, Rama VI Road Thung Phyathai Rachadevi, 10400 Bangkok, Thailand, scwvr@mahidol.ac.th

Vladislav V. Yudanov Physical-Technical Institute, Volgograd State University, University Avenue, 400062 Volgograd, Russia, Yudanov-VolSU@yandex.ru

Chetan M. Zade School of Chemical Sciences, North Maharashtra University, Jalgaon, 425001 India, zadecm2007@ rediffmail.com 
